Wilhelm von Humboldt

Briefe

Band 1 


\title{
Wilhelm von Humboldt Briefe
}

Historisch-kritische Ausgabe

\author{
Abteilung 1: \\ Briefe bis zum Beginn der diplomatischen Laufbahn \\ 1781-1802
}




\title{
Wilhelm von Humboldt Briefe
}

\author{
Band 1 \\ 1781-Juni 1791 \\ Herausgegeben und kommentiert \\ von Philip Mattson
}


ISBN 978-3-05-006329-4

e-ISBN 978-3-05-010312-9

\section{Bibliografische Information der Deutschen Nationalbibliothek}

Die Deutsche Nationalbibliothek verzeichnet diese Publikation in der Deutschen Nationalbibliografie; detaillierte bibliografische Daten sind im Internet über http://dnb.dnb.de abrufbar.

(C) 2014 Akademie Verlag GmbH, Berlin

Ein Unternehmen von De Gruyter

Layout \& Satz: Moritz Ahrens \& Leonard Keidel

Druck \& Bindung: Beltz Bad Langensalza GmbH, Bad Langensalza

@ Gedruckt auf säurefreiem Papier

Printed in Germany

www.degruyter.com/akademie 
Frau Marie-Agnes von Heinz,

ohne deren entschlossenes Handeln diese Edition nicht denkbar wäre, in dankbarer, herzlicher Verehrung gewidmet. 
